\title{
Pengaruh Metode Pembelajaran dan Rasa Nasionalisme Terhadap Hasil Belajar Ilmu Pengetahuan Sosial (IPS)
}

\author{
Sinta Maria Dewi \\ Pendidikan Guru Sekolah Dasar, FKIP, Universitas Buana Perjuangan Karawang \\ JI HS. Ronggo Waluyo, Puseurjaya, Telukjambe Timur, Karawang, Jawa Barat, \\ Indonesia
}

Corresponding author's: sintamaria@ubpkarawang.ac.id

\section{Effect of Learning Methods and Sense of Nationalism on Social Sciences Learning Outcomes (IPS)}

\begin{tabular}{l} 
Article info: \\
\hline Article History \\
Available online \\
30 September 2018 \\
\hline Keywords: \\
learning methods, \\
sense of \\
nationalism and \\
social studies \\
learning outcomes \\
\hline
\end{tabular}

\begin{abstract}
Abstrak
Penelitian ini bertujuan untuk mengetahui Pengaruh Metode Pembelajaran dan Rasa Nasionalisme terhadap Hasil Belajar IPS di SDN Anggadita V Klari Karawang. Peneltian ini menggunakan treatment by level desain $2 \times 2$. Untuk memenuhi persyaratan analisis dilakukan pengujian normalitas data menggunakan uji Liliefors dan homogenitas menggunakan uji Barlett. Setelah analisis varian (ANAVA) dua jalur untuk menguji perberdaan nilai rerata absolut antara dua kelompok yang dipasangkan, dilanjutkan uji Tukey untuk melihat interaksi kelompok dengan mengacu taraf signifikan $\dot{\alpha}=0,01$ dan $\dot{\alpha}=0,05$. Temuan penelitian ini menunjukkan bahwa: (1) Secara keseluruhan, metode pembelajaran karyawisata lebih tinggi daripada pembelajaran menggunakan metode inquiry. (2) Terdapat interaksi antara metode pembelajaran dan rasa nasionalisme terhadap hasil belajar IPS. (3) Hasil belajar IPS melalui metode karyawisata lebih tinggi dari hasil belajar IPS melalui metode inquiry yang sama-sama memliki rasa nasionalisme tinggi, diterima. (4) Hasil belajar IPS melalui metode karyawisata lebih rendah dari hasil belajar IPS melalui metode inquiry yang sama-sama memiliki rasa nasionalisme rendah. Berdasarkan hasil penelitian dapat disimpulkan bahwa metode pembelajaran dan rasa nasionalisme berpengaruh terhadap hasil belajar siswa. Rekomendasi bagi guru adalah agar menerapkan metode pembelajaran sebagi salah satu cara untuk meningkatkan hasil belajar IPS siswa.
\end{abstract}




\begin{abstract}
(2) There is an interaction between learning methods and a sense of nationalism towards the learning outcomes of social studies. (3) Social studies learning outcomes through higher field trip methods from social studies learning outcomes through inquiry methods which share a high sense of nationalism are accepted. (4) The results of social studies learning through a field trip method are lower than the results of social studies learning through inquiry methods which both have a low sense of nationalism. Based on the results of the study it can be concluded that the learning method and sense of nationalism affect student learning outcomes. The recommendation for teachers is to apply the learning method as a way to improve student social studies learning outcomes.
\end{abstract}

\title{
PENDAHULUAN
}

Berdasarkan Undang-undang Republik Indonesia Nomor 20 Tahun 2003 tentang Sistem Pendidikan Nasional bahwasannya Pendidikan berfungsi mengembangkan kemampuan dan membentuk watak serta peradaban bangsa yang bermartabat dalam rangka mencerdaskan kehidupan bangsa. Pendidikan di Indonesia sangat mendambakan adanya pembaharuan pendidikan atau inovasi pendidikan dalam dunia pendidikan di Indonesia. Seiring dengan hal tersebut kemajuan ilmu pengetahuan dan teknologi mengalami perkembangan yang sangat pesat sehingga menuntut adanya sumber daya manusia yang berkualitas untuk mengatasi berbagai permasalahan yang timbul karena perkembangan tersebut. Peningkatan sumber daya manusia juga merupakan salah satu syarat untuk mencapai tujuan pembangunan dan kemajuan bangsa dan negara. Salah satu wahana untuk meningkatkan sumber daya manusia yang berkualitas adalah melalui pendidikan.

Pembelajaran merupakan kegiatan belajar mengajar yang dilakukan oleh guru dengan siswa. Proses pembelajaran yang dilakukan siswa dan guru untuk mencapai suatu tujuan pendidikan. Salah satu cara untuk mencapai tujuan pendidikan di dalam pembelajaran dengan mengoptimalkan peran guru sebagai pengajar. Tujuan pendidikan dapat tercapai dengan optimal apabila peran seorang guru dapat menyajikan pembelajaran secara kreatif dan variatif bagi siswa. Pernyataan ini didukung oleh E. Mulyasa (2006: 164) bahwa proses pembelajaran pada hakikatnya untuk mengembangkan aktivitas dan kreativitas peserta didik melalui berbagai interaksi dan pengalaman belajar. Pembelajaran yang kreatif membuat siswa merasa senang dalam kegiatan pembelajaran. Ketika siswa merasa senang dengan pembelajaran yang diberikan oleh guru maka siswa dapat memaknai pelajaran dengan mudah dan akibatnya prestasi belajar siswa tercapai dengan optimal. Pencapaian prestasi belajar yang optimal merupakan ciri tercapainya tujuan pendidikan dan meningkatnya kualitas pendidikan.

Prestasi belajar yang didapatkan siswa ditentukan oleh beberapa faktor, salah satu faktor penting yaitu metode pembelajaran yang digunakan oleh guru. Metode pembelajaran yang sesuai diterapkan di Sekolah Dasar merupakan metode yang dapat memberikan pengalaman langsung kepada siswa. Sesuai dengan karakteristik siswa Sekolah Dasar yaitu operasional konkret bahwa usia siswa sekolah dasar dalam kegiatan belajar mengajar diperlukan benda benda-benda konkret agar siswa lebih memaknai pembelajaran. Selain benda konkret dalam pembelajaran, keterlibatan siswa secara keseluruhan juga mempengaruhi prestasi belajar.

M Gorky Sembiring (2009: 46) menyatakan apabila siswa diberitahu maka akan lupa, jika siswa diperlihatkan maka siswa mungkin ingat, jika siswa dilibatkan maka siswa akan mengerti. Maksud dari kutipan di atas jika siswa hanya mendengar saja maka akan cepat dilupakan, apabila siswa hanya melihat contoh maka siswa mungkin ingat saja, apabila siswa mengalami secara langsung maka siswa akan memaknai apa yang sudah dipelajari. Keterlibatan siswa sangat penting dalam pembelajaran di 
sekolah, karena sekarang ini kurikulum yang berlaku mengutamakan keaktifan siswa dalam belajar yang sering digunakan dengan istilah student center yaitu pembelajaran berpusat pada siswa atau siswa sebagai subjek. Pembelajaran berbasis pada siswa ini memperbaiki pembelajaran yang terdahulu yaitu pembelajaran berpusat pada guru atau sering disebut dengan istilah teacher center.

IImu Pengetahuan Sosial (IPS) mempelajari tentang masyarakat dan lingkungan yang memerlukan keaktifan siswa dan pengalaman langsung bagi siswa dalam kegiatan belajar. Metode yang digunakan dalam pembelajaran IPS memerlukan metode yang sesuai dengan materi, karakteristik siswa, kondisi lingkungan sekitar sekolah, dan siswa sebagai pelaku utama pembelajaran agar prestasi belajar IPS tercapai dengan optimal.

Anak-anak usia sekolah dasar merupakan masa bermain dan aktif bagi siswa dan membutuhkan gerak dalam kegiatan pembelajaran serta berinteraksi langsung dengan apa yang dipelajari. Dalam kenyataan dalam kegiatan pembelajaran di sekolah dasar masih banyak menggunakan pendekatan teacher center yaitu guru sebagai sumber ilmu. SDN Anggaadita IV merupakan salah satu sampel dalam penelitian ini. Sekolah Dasar tersebut termasuk sekolah dengan fasilitas cukup lengkap. Pada proses pembelajaran, guru dalam menyampaikan kompetensi pembelajaran di dalam kelas dengan menggunakan metode ceramah dan belum memanfaatkan lingkungan sekitar dalam pembelajaran secara optimal. Penggunaan metode yang terlalu sering dan tempat pembelajaran yang selalu berada di dalam kelas membuat siswa bosan dalam mengikuti pembelajaran. Dalam kegiatan awal pembelajaran siswa tampak semangat, akan tetapi beberapa menit setelah memasuki pelajaran inti siswa tampak bermain sendiri dikarenakan bosan, akibatnya prestasi belajar siswa menjadi tidak optimal.

Metode Pembelajaran Karya Wisata dimaksudkan agar siswa tidak jenuh dalam pembelajaran karena biasanya mereka belajar di dalam kelas akan tetapi, sekarang pembelajaran bisa dilakukan di luar kelas. Siswa bisa langsung bersentuhan dengan benda yang akan mereka pelajari yang ada di lingkungan tempat mereka belajar dan mereka juga bisa melihat bagaimana keadaan lingkungan sekitar sehingga mampu menimbulkan sikap peduli terhadap lingkungan dan adanya rasa ingin tahu yang tinggi terhadap benda yang mereka lihat. Siswa juga lebih mudah untuk mengerti materi yang diajarkan karena langsung melihat benda yang berkaitan dengan materi. Guru juga bisa menambahkan permainan dalam pembelajaran yang dilaksanakan sehingga siswa tidak hanya mendapatkan ilmu pengetahuan, tetapi juga mendapatkan hiburan yang tentu saja tidak akan membuat siswa menjadi jenuh dan malas.

Menurut Wina Sanjaya (2010: 147), metode adalah cara yang digunakan untuk mengimplementasikan rencana yang sudah disusun dalam kegiatan nyata agar tujuan yang telah disusun tercapai secara optimal. Metode Pembelajaran Karya Wisata sangat tepat diterapkan pada anak sekolah dasar karena kebanyakan dari mereka suka dengan permainan yang berkaitan dengan lingkungan sekitar sehingga membuat anak menikmati pembelajaran yang dilaksanakan karena apabila anak sudah bisa menikmati pembelajaran yang dilaksanakan tentu saja mereka lebih mudah dan cepat untuk menyerap materi pembelajaran.

Menurut Wina Sanjaya (2006) dalam bukunya Muhammad Syarif Soemantri, metode inquiry merupakan serangkaian kegiatan pembelajaran yang menekankan pada proses berfikir secara kritis dan analitis untuk menemukan jawabannya sendiri dari suatu masalah. Dalam penerapan metode inquiry, siswa melakukan pembelajaran dengan penyelidikan dan mengadakan penelitian secara ilmiah. Data yang dikumpulkan bisa di dapat dari tanya jawab guru dengan siswa, dalam pelaksanaan pembelajaran siswa bisa di ajak ke tempat tertentu seperti perpustakaan dan sebagainya. 
Penanaman jiwa nasionalisme perlu dilakukan di sekolah khususnya sekolah dasar, hal ini dikarenakan bahwa sekolah merupakan tempat pendidikan dan pembentukan jiwa serta semangat bagi generasi muda yang akan menentukan masa depan bangsa Indonesia di masa yang akan datang. Nasionalisme dan semangat cinta tanah air harus sejak usia dini ditanamkan pada anak-anak. Tujuannya agar sejak kecil, anak-anak mengenal Indonesia dan memiliki rasa cinta pada bangsa dan negara. Jika sejak kecil sudah memiliki semangat ini, maka kita akan bangga pada generasi yang akan datang, sebab kelak saat dewasa mereka akan ikut memajukan Indonesia dengan penuh semangat. Untuk bisa menanamkan Nasionalisme dan semangat cinta tanah air pada anak-anak, kita memerlukan metode yang tepat, sesuai dengan karakteristik anak-anak usia dini. Salah satu metode yang sesuai yaitu dengan metode karya wisata dan metode inquiry.

Oleh sebab itu peneliti perlu mengadakan penelitian untuk mencari pengaruh media pembelajaran dan rasa nasionalisme siswa terhadap hasil belajar IImu Pengetahuan Sosial (IPS) siswa kelas V di SD Negeri Anggadita V Klari Kabupaten Karawang Provinsi Jawa Barat

\section{METODOLOGI PENELITIAN}

Metode yang digunakan dalam penelitian ini adalah metode eksperimen dengan menggunakan desain treatment by level $2 \times 2$. Dalam penelitian ini terdapat variabel bebas (variable predictor) yaitu metode pembelajaran $\left(\mathrm{X}_{1}\right)$ dan variabel moderat yaitu rasa nasionalisme $\left(\mathrm{X}_{2}\right)$ dan variabel terikat (variable criteria) yaitu hasil belajar IPS (Y).

Instrumen hasil belajar IPS dengan menggunakan tes tertulis, perangkat tes yang digunakan untuk mengukur hasil belajar ini berbentuk tes objektif, yaitu bentuk tes pilihan ganda dengan lima alternatif jawaban dan instrumen rasa nasionalisme dengan menggunakan angket. Untuk pengujian normalitas data dilakukan dengan menggunakan Uji Liliefors dan Uji Homogenitas dengan Uji Barlett. Adapun teknik analisis data yang digunakan yaitu ANAVA dua jalur dan pengujian simple efferct dengan Uji Tuckey.

\section{HASIL PENELITIAN}

Rekapitulasi deskripsi data penelitian untuk masing-masing kelompok dapat dilihat sebagai berikut:

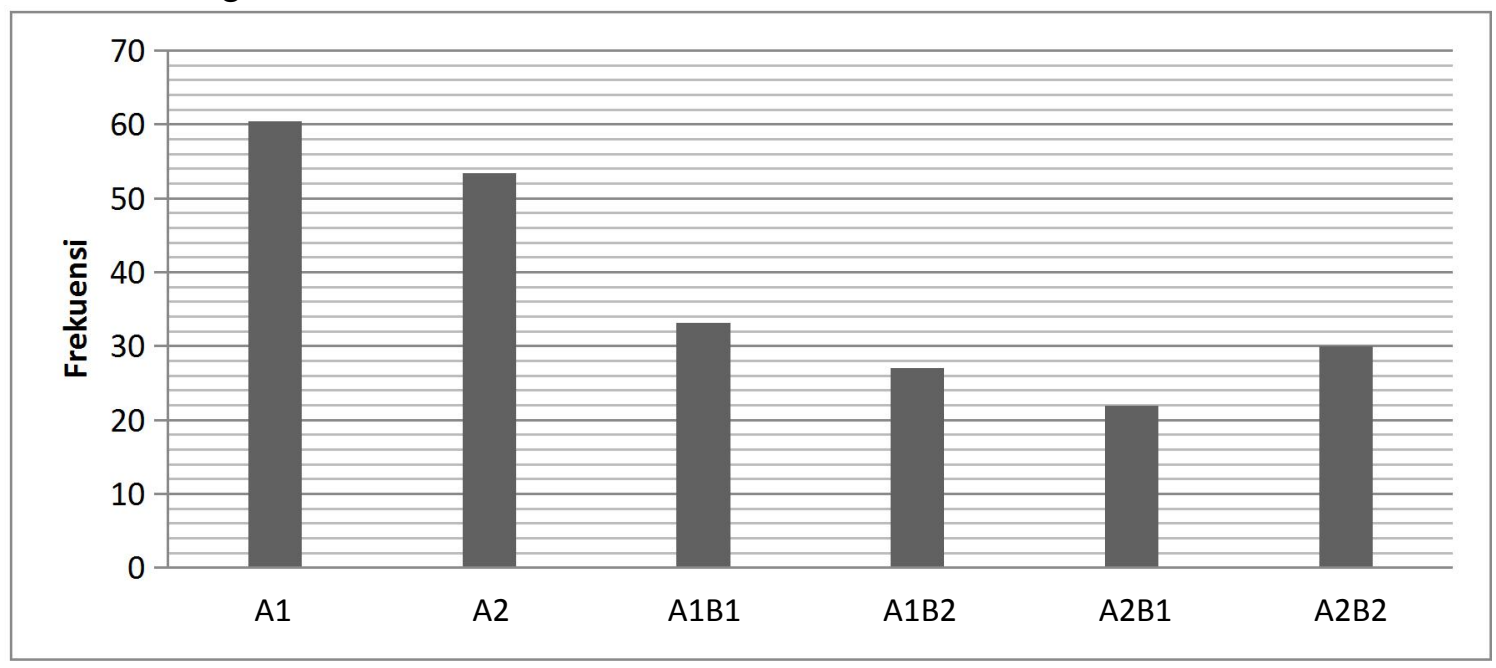

Gambar 1. Histogram Distribusi Frekuensi Skor Hasil Belajar IPS Menggunakan Metode Pembelajaran Berdasarkan Rasa Nasionalisme Yang Dimiliki Siswa 
Berdasarkan rekapitulasi data penelitian diatas, disimpulkan bahwa rata-rata A1 lebih tinggi daripada rata-rata $\mathrm{A} 2$, untuk nilai rata-rata skor A1B1 lebih tinggi daripada A1B2 dan untuk nilai rata-rata skor A2B2 lebih tinggi daripada nilai A2B1.

Pengujian persyaratan analisis untuk uji hipotesis dakam penelitian ini mencakup Uji Normalitas data menggunakan Uji Liliefors dan Uji Homogenitas dengan menggunakanUuji Barlett. Berdasarkan data A1, A2, A1B1, A1B2, A2B2, A2B1 dinyatakan normal dan homogen. Dengan demikian, berdasarkan kedua hasil pengujian persyaratan analisis dapat disimpulkan bahwa persyaratan yang diperlukan untuk analisis varians telah terpenuhi sehingga laya untuk dilakukan analisis lebih lanjut. Untuk menguji hipotesis, terlebih dahulu dilakukan analisis varians dua jalur dengan interaksi (ANAVA 2x2). Hasil perhitungan ANAVA pada tabel 1 sebagai berikut:

Tabel 1. Analisis Variansi untuk melihat Pengaruh Metode Pembelajaran dan Rasa Nasionalisme Siswa terhadap Hasil Belajar IPS

\begin{tabular}{|c|c|c|c|c|c|c|}
\hline \multirow{2}{*}{ Sumber Varians } & \multirow{2}{*}{ JK } & \multirow{2}{*}{$\mathrm{Db}$} & \multirow{2}{*}{ RJK } & \multirow{2}{*}{$F_{\text {hitung }}$} & \multicolumn{2}{|c|}{$F_{\text {tabel }}$} \\
\hline & & & & & $\alpha=0,05$ & $\alpha=0,01$ \\
\hline Metode Pembelajaran (Antar A) & 105,625 & 1 & 105,625 & $31,1936^{*}$ & 4,11 & 7,39 \\
\hline Rasa Nasionalisme (Antar B) & 24,025 & 1 & 24,025 & $7,09516^{*}$ & 4,11 & 7,39 \\
\hline Interaksi AxB & 469,225 & 1 & 469,225 & $\begin{array}{r}138,5734 \\
\text { * }\end{array}$ & 4,11 & 7,39 \\
\hline Dalam & 121,9 & 36 & 3,386111111 & & & \\
\hline Total & 720,775 & 39 & & & & \\
\hline
\end{tabular}

*Signifikan

Hipotesis Pertama, Terdapat pengaruh yang signifikan metode pembelajaran terhadap hasil belajar IPS pada kelompok siswa yang menjadi subjek dalam penelitian ini, atau terdapat pengaruh kolom (A) yang signifikan karena nilai $F_{\text {hit }}(A)=31,1936>$ $F_{\text {tab }}=4,11$ pada taraf sifnifikan $\alpha=0,05$. Dengan demikian dapat disimpulkan bahwa terdapat perbedaan pengaruh yang signifikan antara metode pembelajaran karya wisata dengan metode pembelajaran inquiry terhadap hasil belajar secara keseluruhan. Karena skor rata-rata hasil belajar IPS yang dihasilkan oleh metode pembelajaran karyawisata lebih tinggi dibandingkan dengan hasil belajar IImu Pengetahuan Sosial (IPS) yang dihasilkan oleh metode pembelajaran inquiry.

Pembelajaran dengan menggunakan metode karyawisata membuat materi yang dipelajari disekolah menjadi lebih relevan dan mampu memanfaatkan lingkungan nyata dalam pembelajaran sehingga dapat memenuhi kebutuhan belajar siswa dan memotivasi belajar.

Dilain pihak, metode pembelajaran yang digunakan yaitu metode inquiry, metode inquiry digunakan di dalam kelas dan perpustakaan. Dalam pengumpulan informasi menjadi kurang relevan dan kurang lengkap karena informasi yang didapat hanya dari perpustakaan. Selain itu apabila dalam pengumpulan informasi membuahkan hasil yang salah akan dapat menurunkan motivasi siswa dalam belajar, sehingga diswa dalam belajar menjadi mudah bosan yang sangat mempengaruhi hasil belajarnya. 
Hipotesis Kedua, Terdapat pengaruh faktor interaksi yang signifikan antara metode pembelajaran dengan rasa nasionalieme terhadap hasil belajar IPS pada siswa yang menjadi subjek penelitian ini karena nilai $F_{\text {hit }}(A x B)=138,5734>F_{\text {tab }}=$ 7,39 pada taraf sifnifikan $\alpha=0,01$. Dapat disimpulkan bahwa hasil penelitian pada pengujian hipotesis kedua menunjukkan terdapat pengaruh interaksi antara metode pembelajaran dan rasa nasionalisme terhadap hasil belajar IPS. Artinya pengaruh interaksi antara metode pembelajaran dengan rasa nasionalisme berpengaruh terhadap tinggi rendahnya hasil belajar IPS siswa SD.

Metode pembelajaran merupakan suatu desain pembelajaran inovatif yang sangat bermanfaat bagi para siswa dan pendidik dalam proses belajar mengajar. Dengan adanya metode pengajaran, peran guru menjadi semakin luas. Sedangkan anak didik akan terbantu untuk belajar dengan lebih baik, serta terangsang untuk memahami subjek yang tengah diajarkan dalam bentuk komunikasi penyampaian pesan yang lebih efektif dan efisien.

Nasionalisme merupakan semangat kebangsaan, perasaan kebangsaan, yaitu semangat cinta atau perasaan cinta terhadap bangsa dan tanah air melebihi apapun juga. Penanaman jiwa nasionalisme perlu dilakukan di sekolah khususnya sekolah dasar, hal ini dikarenakan bahwa sekolah merupakan tempat pendidikan dan pembentukan jiwa serta semangat bagi generasi muda yang akan menentukan masa depan bangsa Indonesia di masa yang akan datang. Nasionalisme dan semangat cinta tanah air harus sejak usia dini ditanamkan pada anak-anak. Tujuannya agar sejak kecil, anak-anak mengenal Indonesia dan memiliki rasa cinta pada bangsa dan negara. Jika sejak kecil sudah memiliki semangat ini, maka kita akan bangga pada generasi yang akan datang, sebab kelak saat dewasa mereka akan ikut memajukan Indonesia dengan penuh semangat.

Sementara itu, hasil belajar IPS siswa dipengaruhi oleh faktor ekstrenal dan internal. Faktor eksternal berasal dari guru, antara lain dengan pemilihan guru terhadap metode pembelajarannya. Sedangkan faktor internal berasal dari diri siswa itu sendiri, antara lain rasa nasionalisme. Bagi siswa yang mempunyai rasa nasinalisme tinggi dengan metode pembelajaran karyawisata hasil belajarnya lebih tinggi daripada siswa yang belajar dengan metode inquiry dan sebaliknya. Berdasarkan uraian diatas, terdapat interaksi antara metode pembelajaran dan rasa nasionalisme terhadap hasil belajar IPS siswa SD kelas V.

Hipotesis Ketiga, hasil perhitungan menunjukkan bahwa Uji Tukey, diperoleh nilai $Q=12,27$ dan nilai $Q t=4,33$ pada taraf signifikan $\dot{\alpha}=0,05$. Sehingga hasil pengujian memberikan kesimpulan bahwa hasil belajar IPS pada siswa yang diajar dengan karyawisata lebih tinggi daripada siswa yang diajar dengan metode inquiry dalam meningkatkan hasil belajar IPS bagi siswa yang memiliki rasa nasionalisme tinggi.

Beberapa ciri siswa yang memiliki rasa nasionalisme sebagaimana telah dikemukakan terdahulu, yaitu memiliki semangat cinta tanah air, mengenal Indonesia dan memiliki rasa cinta pada bangsa dan negara.. Siswa memiliki ciri ini akan lebih 
mudah menguasai materi pelajaran yang dipelajari dibandingkan siswa yang tidak memiliki ciri tersebut.

Rasa Nasionalisme dihubungkan dengan metode pembelajaran yang digunakan dalam proses belajar, maka sesuai dengan ciri utama metode karyawisata, metode ini bertujuan agar siswa lebih bersemangat dalam menggali informasi yang berkaitan dengan pahlawan dengan langsung mengunjungi tempat-tempat bersejarah (Lubang Buaya/Monumen Nasional), dan membantu siswa menemukan makna dari apa yang telah dipelajari.

Karakteristik yang dimiliki oleh siswa yang kecenderungan memiliki rasa nasionalisme memberi petunjuk bahwa metode pembelajaran karyawisata akan lebih menguntungkan. Dilain pihak, metode pembelajaran yang digunakan yaitu metode inquiry, metode inquiryd digunakan di sekolah berbeda dengan metode karyawisata yang digunakan langsung ditempat bersejarah.

Berdasarkan uraian diatas, hasil belajar IPS siswa yang memiliki rasa nasionalisme tinggi lebih baik jika menggunakan metode pembelajaran karyawisata daripada yang diajar dengan menggunakan metode inquiry.

Hipotesis Keempat, hasil perhitungan dengan uji Tukey, diperoleh nilai Qhitung= $4,375>Q_{\text {tabel }}=4,33$ pada taraf signifikan $\dot{\alpha}=0,05$. Sehingga hasil pengujian memberikan kesimpulan bahwa hasil belajar IPS pada siswa yang diajar dengan karyawisata lebih rendah daripada siswa yang diajar dengan metode inquiry dalam meningkatkan hasil belajar IPS bagi siswa yang memiliki rasa nasionalisme rendah.

Nasionalisme yaitu memiliki semangat cinta tanah air, mengenal Indonesia dan memiliki rasa cinta pada bangsa dan negara. Siswa memiliki ciri ini akan lebih mudah menguasai materi pelajaran yang dipelajari dibandingkan siswa yang tidak memiliki ciri tersebut.

Jadi rasa nasionalisme ini pada prinsipnya hanya akan sampai pada pemerolehan hasil belajar, mulai dari semangat cinta tanah air, mengenal tanah air, sampai memiliki rasa cinta kepada bangsa dan negara, apabila ia mengalami sendiri, mencari informasi sendiri ditempat bersejarah dalam proses pemerolehan hasil belajar tersebut. Dimana siswa yang memiliki rasa nasionalisme rendah mempunyai karakteristik tidak bersemangat untuk menggali pengetahuan tentang kebangsaaan.

Siswa yang memiliki rasa nasionalisme rendah mengikuti proses pembelajaran apa adanya, sehingga diperlukan tujuan pembelajaran yang tersusun dengan baik. Pemerolehan informasi yang didapat dari buku/referensi dirasa sudah cukup, sehingga pembelajaran di kelas pun rasa cukup. Proses pembelajaran dengan metode inquiry lebih menguntungkan bagi siswa yang memiliki rasa nasionalisme rendah.

Siswa yang memiliki rasa nasionalisme rendah cenderung tidak peduli terhadap lingkungan sekitar. Untuk pembelajaran dengan metode karyawisata bagi siswa yang memiliki rasa nasionalisme rendah cenderung akan membuat pembelajaran tidak bermakna karena pembelajaran hanya akan dijadikan sebagai wisata yang tidak bernilai sejarah sehingga dapat menurunkan motivasi yang berakibat dapat menurunkan hasil belajar siswa.Keadaan ini tentunya dapat memberikan dampak terhadap pencapaian hasil belajar IPS. 
Berdasarkan uraian diatas, hasil belajar IPS siswa yang memiliki rasa nasionalisme rendah lebih baik jika menggunakan metode pembelajaran inquiry daripada yang diajar dengan menggunakan metode karyawisata.

\section{KESIMPULAN}

Berdasarkan hasil pengujian hipotesis dan pembahasan diperoleh kesimpulan yaitu: (1) Hasil belajar IPS siswa antara siswa yang di ajar dengan metode pembelajaran karyawisata lebih tinggi dari hasil belajar IPS siswa yang di ajar dengan metode pembelajaran inquiry (2) Terdapat interaksi antara metode pembelajaran dan rasa nasionalisme terhadap hasil belajar IPS (3) Bagi siswa yang memiliki rasa nasionalisme tinggi dan di ajar dengan metode pembelajaran karyawisata memperoleh hasil belajar IPS yang lebih tinggi dibandingkan siswa yang di ajar dengan metode pembelajaran inquiry (4) Bagi siswa yang memiliki rasa nasionalisme rendah dan di ajar dengan metode pembelajaran karyawisata memperoleh hasil belajar IPS lebih rendah dibandingkan siswa yang di ajar dengan metode pembelajaran inquiry.

Berdasarkan kesimpulan, diajukan saran yang dapat dipertimbangkan dalam peningkatan hasil belajar IPS siswa yaitu :

1. Sebaiknya guru lebih banyak memberikan wawasan kebangsaan kepada siswa agar tumbuh rasa nasionalisme sejak dini dengan lebih sering mengunjungi tempat-tempat bersejarah yang ada di daerah masing-masing atau terdekat dengan lingkungan sekolah.

2. Selama ini pembelajaran IPS disekolah hanya menekankan pada infiormasi, fakta dan hapalan, lebih mementingkan isi daripada proses, kurang diarahkan pada proses berfikir (tingkat tinggi), dan kurang diarahkan pada pembelajaran yang bermakna. Sebaiknya guru menggunakan dan memanfaatkan metode secara maksimal, agar anak didik akan mampu menyerap segala pesan materi yang disampaikan.

3. Orang tua diharapkan dapat memberikan pendidikan kepada anaknya untuk mampu meningkatkan kemampuan anak sesuai dengan tingkat perkembangan anak.

\section{DAFTAR PUSTAKA}

Ahmadi, Khoiru lif. Mengembangkan Pembelajaran IPS Terpadu. Jakarta: PT Prestasi Pustakaraya. 2011

Gunawan, Rudy. Pendidikan IPS Filosofi, Konsep, dan Aplikasi. Bandung:Alfabeta. 2013

Hamka. Modul Pendidikan dan Pelatihan Profesi Guru Sekolah Dasar. Jakarta: Universitas Muhammadiyah Prof Uhamka. 2011

Sanjaya, Wina. Kurikulum dan Pembelajaran. Jakarta: Kencana Prenada Media Group. 2011

Strategi Pembelajaran Berorientasi Standar Proses Pendidikan. Jakarta: Kencana Prenada Media. 2011 
Sumantri, Muhammad. Strategi Pembelajaran Teori dan Praktik di Tingkat Pendidikan Dasar. Jakarta. PT. RajaGrafindo Persada. 2016

Supardan, Dadang. Pembelajaran IImu Pengetahuan Sosial Perspektif Filosofi dan Kurikulum. Jakarta. PT. Bumi Aksara. 2015

Siregar, Evelin. Teori Belajar dan Pembelajaran. Bogor: Ghalia Indonesia. 2010

Sugiyono. Statistika untuk Penelitian. Bandung: Alfabeta. 2007

Sugiyono. Metode Penelitian Pendidikan Pendekatan Kuantitatif, Kualitatif, dan R\&D. Bandung: Alfabeta. 2006 